\title{
AN INVESTIGATION OF MESH INFLUENCE ON Results OF Numerical MOdelling APPLIED IN TEXTILE
}

\author{
Hursa, A.; Rolich, T.; SOMOdI, Z \& \& Rogale, D.
}

Abstract: In this paper the influence of finite element mesh density on accuracy of results is investigated in the example of mechanically weakened zones in clothes, such as vicinity of buttonholes. For this purpose two examples are modelled as corresponding to test specimens for tensile experiments on fabric strip with transverse cut and circular hole. The examples are modelled in a programme developed by authors in Microsoft Visual Basic and in MATLAB software. Four mesh densities are investigated and results in both programs confirm the assumption that with increase of number of finite elements results accuracy is improved.

Key words: clothing technology, fabric, finite element method, mesh density, triangular element
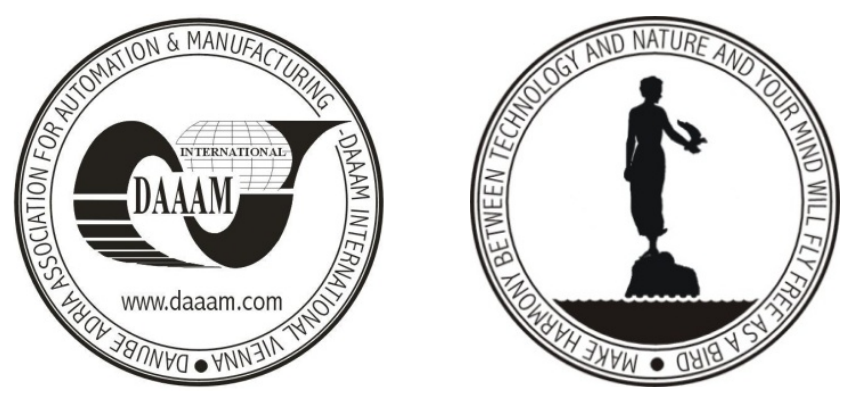

Authors' data: Dr. Hursa, A[nica]; Assist. Prof. Rolich, T[omislav]; Prof. Somodi, [Zeljko]; Prof. Rogale, D[ubravko], Faculty of Textile Technology, University of Zagreb, Prilaz baruna Flipovica 28a,10000, Zagreb, HR, anica.hursa@ttf.hr, tomislav.rolich@ttf.hr, zeljko.somodi@ttt.hr,dubravko.rogale@ttf.hr

This Publication has to be referred as: Hursa, $\mathrm{A}$ [nica]; Rolich, $\mathrm{T}$ [omislav]; Somodi, [Zeljko] \& Rogale, D[ubravko] (2008). An Investigation of Mesh Influence on Results of Numerical Modelling Applied in Textile, Chapter 30 in DAAAM International Scientific Book 2008, pp. 349-358, B. Katalinic (Ed.), Published by DAAAM International, ISBN 978-3-901509-66-7, ISSN 1726-9687, Vienna, Austria DOI: $10.2507 /$ daaam.scibook.2008.30 